Hispania Sacra, LXI

123, enero-junio 2009, 125-146, ISSN: 0018-215-X

\title{
LA BATALLA DEL BIEN Y EL MAL: «PATROCINIO DE ÁNGELES Y COMBATE DE DEMONIOS»**
}

\author{
POR \\ MARÍA TAUSIET \\ Instituto de Historia. Centro de Ciencias Humanas y Sociales-CSIC
}

\begin{abstract}
RESUMEN
En 1652 salió a la luz un libro con el expresivo título de Patrocinio de ángeles y combate de demonios. De acuerdo con su autor se trataba de una «ilustración de los beneficios que hazen los angeles de la guarda a los hombres [...], y también de las astucias y impugnaciones de los demonios.» No obstante, el protagonismo de los demonios era mucho mayor. No hay que olvidar que el tratado incorporaba la intensa experiencia vivida por el autor del libro en las montañas de Jaca durante su período como párroco al declararse una grave epidemia de posesión demoníaca que se prolongó durante cinco años y que afectó a sesenta y dos mujeres.
\end{abstract}

Palabras ClaVE: Ángeles, Demonios, Providencia, Posesión Demoníaca, Contrarreforma, Aragón.

\section{GOOD VERSUS EVIL: «PATRONAGE OF ANGELS AND COMBAT OF DEMONS»}

\begin{abstract}
Patronage of Angels \& Combat of Demons was the eloquent title of a book published in 1652. According to its author, the book was 'an illustration of the benefits conferred on men by guardian angels [...], and also of the ploys and challenges of demons.' Nevertheless the prominence of demons was much more ob-
\end{abstract}

\footnotetext{
* Hay una traducción al inglés en «Patronage of Angels \& Combat of Demons: Good versus Evil in 17th Century Spain», Peter Marshall y Alexandra Washam (eds.), Angels in the Early Modern World, ISBN: 0-521-84332-4 Cambridge, Cambridge University Press, 2006.
} 
vious. It is important to notice that the treatise reflected the author's intense experience in the mountains near Jaca during the time he spent as a parish priest, when a serious epidemic of demonic possession broke out. It was to last five years, and sixty-two women were allegedly affected.

KEY WORDS: Angels, Demons, Providence, Demonic Possession, CounterReformation, Aragon.

Recibido/Received 05-03-2008

Aceptado/Accepted 14-07-2008

«En lucha perpetua estarán necesariamente y para siempre, sin que se encuentre ninguna solución»

John Milton ${ }^{1}$

\author{
«Es continua la guerra, y lo será hasta que se dé fin al mundo, entre los santos ángeles \\ y demonios» \\ Francisco Blasco Lanuza ${ }^{2}$
}

La mítica batalla celestial entre ángeles rebeldes y leales que habría tenido lugar antes de la creación del mundo, terminando con la derrota de los primeros y su consiguiente precipitación en el abismo, encontró un eco extraordinario en la Europa del siglo XVII. Según numerosos testimonios de la época, las fuerzas del bien y el mal, cuyos enfrentamientos continuaron a partir de la caída, renovaron entonces sus denodados combates con fuerza inusitada en los rincones más remotos de la Cristiandad. Para los teólogos que se ocuparon del tema, dicho estado de cosas constituía una prueba irrefutable de la obligación perentoria por parte de los fieles de apoyar al bando de los justos frente a los continuos e inesperados acosos de los espíritus infernales.

En 1652 salió a la luz en la imprenta del monasterio de San Juan de la Peña, en pleno Pirineo aragonés, un libro con el expresivo título Patrocinio de ángeles y combate de demonios. De acuerdo con su autor, el monje benedictino Francisco Blasco Lanuza, por entonces abad del monasterio, se trataba de una «ilustración de los beneficios que hazen los angeles de la guarda a los hombres, desde que Dios cria sus almas hasta que suban al cielo en la resurreción general, y también de las astucias y impugnaciones de los demonios» ${ }^{3}$. En realidad, la obra venía a ser de algún modo una continuación de otro tratado escrito quince años antes por el mismo autor sobre los favores prodigados por los ángeles de la guarda a todas las criaturas y especialmente a los hombres, como manifestación

\footnotetext{
1 John Milton, El Paraíso perdido [1 $1^{\text {a }}$ ed., Londres, 1667], libro VI, versos 693-694 (trad. esp. de Esteban Pujals, Madrid, Cátedra, 1986).

2 Francisco Blasco Lanuza, Patrocinio de ángeles y combate de demonios, San Juan de la Peña, 1652 , p. 474.

${ }^{3}$ Francisco Blasco LanuZa, Patrocinio, cubierta. 
de la Divina Providencia ${ }^{4}$. No obstante, en esta ocasión, el protagonismo de los demonios (cuyo combate o contra-custodia constante tratarían de contrarrestar las acciones angelicales) era mucho mayor ${ }^{5}$.

El segundo tratado incorporaba la intensa experiencia vivida por el clérigo en las montañas de Jaca (Huesca) durante su período como párroco de Sandiniés al declararse una grave epidemia de posesión demoníaca en la localidad y en la vecina Tramacastilla que iba a durar cinco años (1637-1642) y que afectó al menos a sesenta y dos mujeres. Como responsable espiritual de la localidad, Francisco se encargó personalmente de exorcizar a muchas de las poseídas mientras duró el mal o, según su propia expresión, «la fiera invasión de ejércitos infernales ${ }^{6}$. Esta vivencia afectó su ánimo hasta el punto de sentirse él mismo acosado frecuentemente por demonios que lo perseguían por culpa de sus pecados, lo que lo llevó a una reflexión profunda acerca de las causas por las que Dios permitía tales desgracias y los posibles remedios contra estos hostigamientos ${ }^{7}$.

Las expresiones del autor en primera persona acerca de su alta implicación emocional en los hechos son variadas y suficientemente significativas. Ante el escaso éxito de los exorcismos realizados en una de las supuestas endemoniadas o «espiritadas» que, arrastrándose por el suelo «como culebra», no dejaba de aullar, el propio Francisco confesó haber atado con su estola a la mujer por el cuello para contenerla, lo que posteriormente le llevaría a confesar:

«No sabia que me hazer, porque parecia mis pecados avian puesto candados en las puertas de la Divina clemencia. Pareceme que fue una de las mayores afliciones que tuve en mi vida» ${ }^{8}$.

La situación no era para menos. De hecho, los acontecimientos descritos por el clérigo conmovieron profundamente la vida social y económica de las locali-

\footnotetext{
${ }^{4}$ Francisco Blasco LanUZa, Beneficios del glorioso angel de nuestra guarda y efetos del govierno de Dios invisible, Zaragoza, 1637.

5 Sobre el combate secular entre ángeles y demonios, vid. Michel RoucHE, «Le combat des saints anges et des démons: la victoire de Saint Michel», en Santi e Demoni nell'alto medioevo occidentale ( secoli V-XI), Spoleto, 1989, pp. 533-560, y Arturo Morgado GARcía, «Ángeles y demonios en la España del Barroco», Chronica Nova, 27, 2000, pp. 107-130.

${ }^{6}$ Francisco Blasco LanuZa, Patrocinio, p. 855.

7 Existe un indudable paralelismo entre las experiencias relatadas por Blasco Lanuza y las de su contemporáneo, el jesuita francés Jean-Joseph Surin, que desempeñó un importante papel como exorcista en Loudun y que llegó a creerse él mismo poseído por los demonios cuando trataba de ahuyentarlos. Vid. Michel de Certeau, La possession de Loudun, París, Julliard, 1970, y La Fable Mystique, XVIe-XVIIe siècle, París, Gallimard, 1982. Vid. También, DE Moshe SLuHovsKy, «The Devil in the Convent», American Historical Review, 107 (5), 2002, pp. 1379-1411, y Believe not every spirit. Possession, mysticism and discernment in Early Modern Catholicism, Chicago y Londres, The University of Chicago Press, 2007.

8 Francisco Blasco LanuZa, Patrocinio, p. 860.
} 
dades afectadas hasta el punto de que sus habitantes, ante la abundancia de mujeres enfermas o poseídas (en cualquier caso, imposibilitadas para llevar una vida normal), se vieron forzados a abandonar sus actividades cotidianas, lo que redundó aún más en su pobreza endémica. Según una carta dirigida por los párrocos de ambas localidades al tribunal inquisitorial de Zaragoza en mayo de 1639 , esto es, casi dos años después de que comenzaran a manifestarse los síntomas atribuidos a la posesión:

«Los lugares que la padecen, por ser tierra tan fragosa y esteril, que es lo mas alto del Pirineo, estan con la esterilidad imposibilitados del todo, sin caudal comun. Y los particulares, muy menesterosos y necesitados, pues no pueden trabajar sus aciendas por sus personas: unas por estar obsesas y otras por cuydar dellas. Todo son asombros y pasmos de gran calamidad, particularmente [entre] los padres que tienen entre las inficionadas treinta o mas doncellas para tomar estado»9.

Tal y como constaba en la carta, todo había comenzado cuando, a finales de octubre de 1637, se descubrió en varias mujeres «un genero de enfermedad oculta [...] y tan rara que tendidas cahian en tierra sin uso de razon ni sentido y entumecidas las gargantas, dando voces en grito como si las aogaran, con acidentes muy frequentes y extraordinarios» ${ }^{10}$. Dada la incapacidad de los médicos para remediar tales males, fueron los párrocos citados quienes se hicieron cargo de la situación. Pero a medida que aumentaban las oraciones y exorcismos, ascendía también el número de posesas o «espiritadas», así como la variedad de los síntomas manifestados por las afectadas: «mortales congojas y ansias de muerte [...] tullimientos [...] continuos ypos, suspiros inmediatos, risas incesantes, llantos, melancolias, vomitos, calenturas ardientes, dolores de yхаda vehementisismos, del vientre, estomago y caveza» ${ }^{11}$. A ello se añadía un irrefrenable rechazo por lo sagrado: muchas decían no poder orar en voz alta en la iglesia ni ver la hostia consagrada, «presentándoseles a veces negra», tampoco confesarse ni recibir la comunión, además de experimentar una particular inquina por el rosario y en especial por la celebración de la Eucaristía.

Ambos párrocos aceptaron como válida desde un principio la interpretación que atribuía al diablo una violenta invasión o posesión de las afectadas, lo que los llevó a procurar todos los remedios espirituales disponibles: además de las oraciones y exorcismos, «procesiones devotas, andando todos a pies descalços por tierra fragosa» ${ }^{2}$, ayunos, etc. De este modo, como afirma Ángel Gari, los pueblos

${ }^{9}$ Carta de Francisco Blasco Lanuza y Matías Jiménez al Tribunal de Zaragoza (copia enviada a la Suprema el 17 de diciembre de 1639). Archivo Histórico Nacional (AHN), Sección Inquisición (Inq.), Libro (Lib.) 976, fol. 305v.

${ }^{10}$ Idem, fol. 305r.

${ }^{11}$ Idem, fols. 304r.-305v.

${ }^{12}$ Francisco Blasco Lanuza, Patrocinio, p. 836. 
de Sandiniés y Tramacastilla llegaron a convertirse durante un tiempo en auténticos «centros de penitencia» ${ }^{13}$. No obstante, la supuesta pasividad y resignación de sus habitantes no era tal. Lejos de convertir al diablo en el único responsable de lo sucedido, muy pronto se señaló como culpables a varios individuos considerados brujos y, por tanto, capaces de maleficiar a quienes lo desearan. El principal acusado era Pedro de Arruebo, joven labrador poderoso, rico y atractivo, de carácter caprichoso y violento, cuyo principal empeño era gozar carnalmente de las mujeres. Tenía varios cómplices entre los que destacaban Miguel Guillén, sastre y gaitero ocasional, audaz, bravucón, mujeriego, bebedor y jugador, como su amigo, y Juan de Larrat, cirujano bearnés que, por su oficio, tenía fácil acceso a muchas pacientes a quienes trataba de engatusar mediante sus curas.

Pedro de Arruebo y sus cómplices fueron procesados por el Santo Oficio en 1638, previa intimación del gobernador de Aragón ${ }^{14}$. Pese a ello, los síntomas de posesión continuaban manifestándose en las «espiritadas» de forma alarmante. De ahí que los dos párrocos solicitaran de nuevo la intervención de la Inquisición, aunque en esta ocasión no la del tribunal zaragozano, sino la del órgano central del Santo Oficio para todo el territorio español, el famoso Consejo de la Suprema y General Inquisición, conocido habitualmente como Suprema. Según una nueva carta fechada en octubre de 1639 (que aparece reproducida en el tratado de Blasco Lanuza sobre los ángeles y los demonios) ambos párrocos no ignoraban las diligencias previas llevadas a cabo por el Santo Oficio de Aragón, pero, dado que el mal «en lugar de remediarse» iba en aumento, requerían el apoyo y ayuda del Inquisidor General, «por ser la suprema proteccion de la santa fe, y el sol que despeja las tinieblas de magos, herejes y supersticiosas hechizeras» ${ }^{15}$. Más aún, en virtud de la gravedad del episodio de posesión demoníaca y de la nula eficacia de los remedios probados hasta entonces, solicitaban la intervención del propio rey Felipe IV, a quien pedían que proveyera el envío a estos valles de exorcistas de reconocido prestigio:

«Suplican a Vuestra Señoria Ilustrissima estos sus afligidos siervos de noticia del succeso a su Magestad, que Dios guarde, para que ponga su atención en mandar a personas

13 Ángel Gari LacruZ, Brujería e Inquisición en el Alto Aragón en la primera mitad del siglo XVII, Zaragoza, DGA, 1991, p. 168.

${ }^{14}$ Conviene tener en cuenta que sobre Pedro de Arruebo recayeron las tres jurisdicciones españolas con competencia en la época para castigar el crimen de brujería: episcopal, seglar e inquisitorial. El proceso de 1638 venía precedido de otras acciones judiciales contra el reo, como la llevada a cabo en 1633 por el obispo de Jaca, quien «le havia condenado en reclusion en cierta hermita y con ciertas penas» (Relación de causa de Pedro de Arruebo, 1635, AHN, Inq., Lib. 992, fol. 203v). En cuanto a los conflictos entre jurisdicciones y al predominio de la Inquisición en este caso, resulta significativa la advertencia de los inquisidores de Zaragoza al mencionado obispo de Jaca en 1634 de «que no deviera entrar en esta causa, sino remitirla al Santo Oficio» (Relación de causa de Pedro de Arruebo, 1635, AHN, Inq., Lib. 992, fol. 204r).

15 Francisco Blasco LanuZa, Patrocinio, p. 837. 
de conocida virtud y particular gracia de sugetar demonios que acudan a tan christiano empleo, que siendo el sucesso tan raro, tambien se requiere especial solicitud» ${ }^{16}$.

La incuestionable unión de los intereses políticos y religiosos representada por la Inquisición se evidencia en los términos en que aparecía formulada la petición de apoyo a la corona española. En su carta, los dos rectores subrayaban el hecho de que, si al final Satanás era vencido gracias al envío de exorcistas competentes, ello supondría un triunfo para los católicos. En esta ocasión, además, a tan escasos kilómetros de la Francia protestante, el éxito podría ser mucho más celebrado:

«Circunstancia es de particular atencion la que se a de considerar que estamos en frontera de Francia por la parte que ay luteranos, calvinistas y atehistas que con la noticia deste estrago del demonio estan a la mira del suceso contemplando la virtud de Nuestra Santa $\mathrm{Fe}$, a la que no ha de resultar pequeño lustre con el reparo desta calamidad» 17 .

La solicitud fue atendida, pues al cabo de unos meses Felipe IV ordenó al inquisidor del reino de Aragón, Bartolomé Guijarro y Carrillo, que se desplazara personalmente a la montañosa localidad de Tramacastilla acompañado del séquito que considerara necesario para averiguar el origen de lo ocurrido y poner fin a tan graves disturbios. La impresión recibida por el inquisidor a su llegada a la localidad el 1 de julio de 1640, después de tres jornadas a caballo desde Zaragoza, no pudo ser más triste. Como él mismo escribiría unos días más tarde, «aunque tenia mucha noticia del mal [...] no entendi que fuera tanto ni tan cierto hasta que por vista de ojos le vi, toque y palpe» ${ }^{18}$. La multiplicación de desmayos, gritos y convulsiones entre las mujeres afectadas era tal que, después de varias semanas, el inquisidor llegó a declarar que «si en alguna ocasion se le puede dar credito al demonio es en esta» ${ }^{19}$. Fuera por autosugestión o por una agresión exterior efectiva, a los dos meses de su estancia en aquellas tierras, Bartolomé Guijarro falleció repentinamente sin poder finalizar su cometido. La opinión, incluyendo el clero y los facultativos, interpretó su muerte como producto de un maleficio provocado por los mismos brujos acusados de haber endemoniado a las espiritadas ${ }^{20}$.

\footnotetext{
16 Idem.

${ }^{17}$ Memorial de Bartolomé Guijarro y Carrillo al Tribunal de Zaragoza sobre su visita a Tena (sin fecha), AHN, Inq., Lib. 976, fols. 306 r y v.

18 Carta de Bartolomé Guijarro y Carrillo al Tribunal de Zaragoza (recibida en Madrid el 17 de julio de 1640), AHN, Inq., Lib. 976, fol. 347r.

19 Carta de Bartolomé Guijarro y Carrillo al Tribunal de Zaragoza (recibida en Madrid el 7 de agosto de 1640), AHN, Inq., Lib. 976, fol. 393r.

20 «[A]cerca de esta enfermedad y muerte del inquisidor Doctor Don Bartolome Guijarro [...] se a hablado que la havria causado algun maleficio [...] y esta sospecha se a fundado [...] en que al dicho inquisidor le hurtaron un par de escarpines, calcetas, calzoncillos [y] una camisa.» Carta de Blas Alexandre de Lezaeta al Tribunal de Zaragoza (recibida en Madrid el 15 de septiembre de 1640), AHN, Inq., Lib. 976, fol. 397r.
}

Hispania Sacra, LXI

123, enero-junio 2009, 125-146, ISSN: 0018-215-X 
A la vista de lo ocurrido, su sucesor, el inquisidor Blas Alexandre de Lezaeta, en vez de desplazarse personalmente al lugar de los hechos, decidió que fueran las posesas quienes acudieran a los tribunales inquisitoriales de Zaragoza para ser examinadas, interrogadas y exorcizadas:

«Mando el Santo Tribunal, despues de la muerte de su Inquisidor, llevar seys de las exercitadas del lugar de Tramacastilla, en compañia de su rector, a la Ciudad de Zaragoça, para ver por experiencia la verdad [...] Alli estuvieron quatro meses, acudiendo al Consistorio todos los dias, dos horas por la mañana y dos por la tarde» ${ }^{21}$.

Pasado este tiempo, las seis parecían curadas y el problema resuelto, por lo que fueron enviadas de nuevo a sus casas. Sin embargo, como relata Blasco Lanuza en su segundo tratado, aunque «algunas de estas arrepticias se libraron alli [y] otras mostraron quedar con salud, despues, en Tramacastilla, bolvieron a ser molestadas como antes ${ }^{22}$. Pese a todo, el nuevo inquisidor dio por zanjada la intervención del Santo Oficio y transfirió la responsabilidad del auxilio espiritual de las afectadas «a los prelados, encargandoles que, como cosa que les toca a ellos, cuyden del remedio de ellas» ${ }^{23}$. A partir de ese momento (enero de 1641), no se conservan más datos procedentes de los archivos inquisitoriales, aunque sabemos por Blasco Lanuza que los síntomas de la epidemia persistirían al menos durante un año más.

Al margen del interés intrínseco de los episodios brevemente expuestos, conviene hacer hincapié en la literatura a que dieron lugar. Aparte de ciertas referencias más bien sensacionalistas y tendentes a exagerar el número de endemoniadas ${ }^{24}$, destacan las versiones de tres de los clérigos que participaron directamente en los acontecimientos. Como veremos a continuación, las narraciones representan tres formas muy diferentes de entender la batalla entre los principios del bien y del mal, lo que se relaciona directamente con la experiencia personal de cada uno de los implicados. De manera sintética podría decirse que el primer relato, de un optimismo simplista, presenta la oposición en-

\footnotetext{
${ }^{21}$ Francisco Blasco LanuZa, Patrocinio, p. 837.

22 Idem.

${ }^{23}$ Carta de Bartolomé Guijarro y Carrillo al Tribunal de Zaragoza (recibida en Madrid el 17 de julio de 1640), AHN, Inq., Lib. 347, fol. 328r.

${ }^{24}$ Según la noticia de los Avisos Históricos de José Pellicer (4 junio de 1640), recogida posteriormente en el Semanario Erudito de Antonio Valladares (Madrid, 1787-1791, tomo 31, p. 127): «En Zaragoza ha celebrado Auto de Fe la Santa Inquisición. Entre varios numerosos delincuentes salió a él un caballero muy conocido llamado Pedro de Arruebo, señor de la Artosa, porque metió demonios en muchos lugares con quien tenía odio y endemonió a más de mil y seiscientas personas. Diéronle doscientos azotes y quedó condenado a galeras.» Sin llegar a aventurar una cifra tan alta, Luisa María de Padilla, en su tratado Elogios de la verdad e invectiva contra la mentira aseguraba que, mientras ella escribía, en dos lugares de las montañas de Aragón se habían descubierto más de doscientas cincuenta mujeres endemoniadas por un solo hombre (Zaragoza, 1640, pp. 539-540).
} 
tre el bien y el mal como una lucha material en la que el bien acaba venciendo gracias a determinados actos heroicos. El segundo relato, profundamente pesimista, representa la espiritualización de una batalla sin cuartel, casi entre iguales, en la que el mal tiene muchas posibilidades de terminar imponiéndose. Por último, en la tercera versión, de un optimismo conscientemente elaborado, la lucha inmaterial entre los opuestos empieza inclinándose a favor del mal, lo que no es sino mera apariencia, percibida por aquellos que no alcanzan a comprender los intrincadas vías por las que el bien se abre paso de forma inexorable.

El trinitario descalzo Fray Luis de la Concepción, por su fama como exorcista acreditado, había formado parte del séquito que acompañó al inquisidor Guijarro en la expedición ordenada por el rey. Años después escribió un tratado titulado Práctica de conjurar, en el que dedicaba una parte a los «prodigiosos sucessos [...] que sucedieron [...] en la villa de Tramacastilla, montañas de Jaca, valle de Tena» 25 . A diferencia de la crisis espiritual que los acontecimientos relatados provocarían tanto en el inquisidor Guijarro como en Blasco Lanuza, el tono de Fray Luis de la Concepción es decididamente triunfante. Sea por su naturaleza visionaria, por expresarse de manera metafórica o, como sugiere Ángel Gari, porque «con su libro pretendía revalorizar su prestigio y fama de exorcista privilegiado» 26 , el fraile se presenta como una suerte de mago capaz de contrarrestar con sus poderes todo tipo de portentos causados por el Maligno. En uno de sus relatos más llamativos, tras ordenar a los demonios que se manifestasen en la iglesia de Tramacastilla, cuenta que

«repentinamente mas de docientas mugeres [...] fueron levantadas en el ayre, que casi tocaban la bobeda de dicha iglesia [...] y no contento con esto, Lucifer [...] mando subiessen por el ayre a lo alto de la iglesia todos los bancos y escaños grandissimos que avia» 27 .

Entonces él mismo, dirigiéndose a Lucifer, exclamó:

«Dragon infernal, ¿yo avia de admitir tus embites? Yo les mandare [...] que baxen todas las criaturas que subieron, primero los bancos y escaños, y despues las criaturas racionales, sin hazer daño alguno, y sea todo puesto en sus lugares, sin discrepar un punto [...] Apenas fue puesto dicho precepto [...] quando luego al punto [...] començaron a baxar dando vueltas alrededor, primero los bancos y escaños, y luego las mujeres, y todo puesto en los mismos lugares que antes ocupaban [...] ¿Quien, a vista de maravillas tantas, no avia de prorrumpir en lagrimas?» 28 .

\footnotetext{
${ }^{25}$ Fray Luis DE LA CONCEPCIÓN, Practica de conjurar en que se contienen exorcismos y conjuros contra los malos espiritus de qualquiera modo existentes en los cuerpos humanos, assi en mediacion de supuesto, como de su iniqua virtud, por qualquier modo y manera de echizos $\left[1^{\mathrm{a}}\right.$ ed., Alcalá de Henares, 1673], Madrid, 1721, p. 140.

26 Ángel GARI, op. cit., p. 170.

${ }^{27}$ Fray Luis DE LA CONCEPCIÓN, op. cit., pp. 143-144.

${ }^{28}$ Idem, pp. 146-149. 
A juzgar por los testimonios contenidos en el tratado del fraile, los demonios habían provocado asimismo una gran tormenta de granizo, que él contuvo milagrosamente, y el hecho de que seis mujeres endemoniadas cuando intentaban confesarse fueran arrebatadas por el aire y sacadas volando a través de la puerta de la iglesia hasta ser colgadas por las puntas de los pies «de los mas eminentes riscos y peñas de aquellos montes Pirineos», quedando «como si sus pies fueran cabeças, y las cabeças pies» ${ }^{29}$. Fray Luis decidió suplicar al inquisidor Bartolomé Guijarro que ordenara volver a sus puestos a los seis confesores, ya que estaba convencido de que de ese modo volverían también las seis penitentes, como así sucedió.

La versión del inquisidor Guijarro contenida en el memorial de su visita a aquellas tierras no sólo elude la mención de tales sucesos, sino de cualquier otro incidente concreto. Más allá de lo anecdótico, su informe constituye una interesante especulación sobre la presencia y poderes del demonio y, en el fondo, una búsqueda de sentido al sufrimiento que tanta mella iba a dejar en sus propias carnes. En este sentido, resulta sintomático comprobar cómo, tras un esmerado repaso a través de algunos de los tratados de demonología más prestigiosos de la época ${ }^{30}$, cuando expresa su opinión personal sobre el origen y el porqué del mal, el edificio teórico sobre el que había asentado su discurso comienza a derrumbarse.

A la hora de enfrentar las nociones de bien y mal, la preeminencia del primero, representado por los ángeles, se juzga incuestionable hasta el punto de que, en su disquisición, la demonología, aparece como mera sombra de la angelología, sombra de la que apenas conocemos nada salvo sus funestos efectos $^{31}$. Así, mientras Guijarro da por sentada la jerarquía según la cual los ángeles se dividen en nueve órdenes o coros (serafines, querubines, tronos, dominios, virtudes, potestades, principados, arcángeles y ángeles ${ }^{32}$ ), al referirse

${ }^{29}$ Idem, p. 158.

${ }^{30}$ En el memorial de Bartolomé Guijarro sobre su visita al valle de Tena, en el que, según comenzaba confesando, pretendía expresar sus reflexiones personales al respecto («por ser tan singular y rara la materia del processo de Pedro de Arruebo, me a parecido reducir a escrito muy brevemente lo que siento della»), el inquisidor se refería, por este orden, a los siguientes tratados: Antonio DE TORQUEMADA, Jardín de flores curiosas (Salamanca, 1570), Raffaele DELla TORRE, Tractatus de potestate ecclesiae coercendi daemones (1611-12), Girolamo MengHI, Compendio dell'arte essorcistica (Venecia, 1595), Heinrich KrÄMER y Jakob Sprenger, Malleus Maleficarum (Colonia, 1486), Martín DEL Río, Disquisitionum magicarum (Lovaina, 1599), Pedro CIRUElo, Reprobación de las supersticiones y hechicerías (Salamanca, 1538), Francisco DE TORREBLANCA Y VILlalPANDO, Demonologia sive de magia naturali (Mainz, 1623), Jacobus SIMANCAS, Institutiones Catholicae (Valladolid, 1552).

${ }^{31}$ Según Santo Tomás de Aquino, dado que todo lo que existe proviene de Dios, al mal no le puede corresponder existencia, definiéndose únicamente como privación del bien. Vid. Tomás DE AQUINO, Compendium Theologiae, 114, 125-126 y Bill KING, Thomas Aquinas on the Metaphysical Problem of Evil, Quodlibet Journal, 4, (2-3), 2002.

32 Sobre las jerarquías angelicales, vid. David Keck, Angels and Angelology in the Middle Ages, Oxford, Oxford University Press, 1998, pp. 53-65. 
a los demonios, esto es, al enigma del mal, declara abiertamente su incertidumbre. Al final -admite- tan solo podemos suponer que, imitando la distribución angelical, los demonios se dividen también en categorías encargadas de desempeñar diferentes funciones:

\begin{abstract}
«Es cierto, segun todos los doctores afirman, que entre los demonios se guarda orden y prelacion no solo segun su naturaleza [...] sino tambien segun su eleccion para hacer mal al hombre [...] y asi se duda si solamente los de naturaleza menos perfecta obsident homines, quedandose los demas en el infierno. Y parece que si, porque los angeles buenos y de supremo orden como el cherubin y el seraphin no se mezclan en negocios mundanos, sino solamente en la contemplacion divina y amor de Dios, y los de tercera orden ejecutan dichos negocios. Luego lo mismo parece que a de ser de los angeles malos pues, aunque perdieron la gracia, guardan el mismo orden que tenian antes que cayesen, porque se quedaron enteras en ellos las cosas naturales» ${ }^{33}$.
\end{abstract}

No obstante, sigue sin resolver el problema de fondo: por qué Dios, que es todo bondad, permite la existencia del mal y el sufrimiento. Y ahí es donde los titubeos e incongruencias del inquisidor vuelven a revelar la crisis moral que sin duda debió experimentar ante la visión de los padecimientos de que fue testigo. Según las afirmaciones contenidas en su memorial, el demonio puede hacer el mal mediante diversos procedimientos. Unas veces pide licencia a Dios para ello «con boz inteligible, como la de los angeles» ${ }^{34}$; otras veces -la mayoría- da por sentado el permiso divino y aprovecha las ocasiones en que «se halla con las manos livres, supuesto que Cristo se las ato con su muerte» ${ }^{35}$. Una de tales ocasiones, según Guijarro, se produce «cuando el Angel de la Guarda que cada hombre tiene no se lo impide, poniendosele delante, o quando rebelandose [contra] Dios desampara a su encomendado para que el demonio le maltrate y dañe» ${ }^{36}$.

Dicho supuesto contradecía radicalmente una de las premisas más importantes de Francisco Blasco Lanuza -el tercero de los clérigos que escribieron sobre los acontecimientos del valle de Tena-, cuya altura intelectual supera con mucho la de los autores ya mencionados. Tanto en su primera obra dedicada a los ángeles de la guarda como en su segundo tratado sobre los combates entre ángeles y demonios, si había algo innegable para él en medio de los infortunios de este mundo era que:

«no dexa al pecador su Angel, aunque sea muy rebelde a sus consejos [...] el santo Custodio en ningun tiempo desampara al pecador, aunque sea muy obstinado, rebelde y ciego [...] assi sale el sol para los pecadores como para los justos» ${ }^{37}$.

${ }^{33}$ Memorial de Bartolomé Guijarro y Carrillo al Tribunal de Zaragoza sobre su visita a Tena (sin fecha), AHN, Inq., Lib. 976, fols. 306v.-307r.

${ }^{34}$ Idem, fol. 310r.

35 Idem, fol. 310v

36 Idem.

${ }^{37}$ Francisco Blasco LanuZa, Beneficios, pp. 99-101.

Hispania Sacra, LXI

123, enero-junio 2009, 125-146, ISSN: 0018-215-X 
Pese a la suerte terrenal que esperaba a aquellos contumaces que se negaban a arrepentirse, la excomunión, con el consiguiente aislamiento del trato humano ${ }^{38}$, los solícitos ángeles seguían prodigando sus favores incluso a los más mezquinos y perversos:

«No hazen como los Prelados de la Iglesia nuestros amorosos Angeles. Aquellos, con zelo del divino honor, descomulgan a los pecadores rebeldes y privan de los bienes comunes de la Iglesia a los contumaces. Estos, como dice el glorioso Cardenal San Buenaventura, no usan deste medio para convertirles porque si les faltase su favor no podrian salir de su miserable estado [...] Para corregir a un pecador, buen medio es la censura de la Iglesia, [pero] aunque los Angeles y los Prelados procuran la honra de Dios, no conviene que usen de unas mismas armas» ${ }^{39}$.

El optimismo inquebrantable de Blasco Lanuza, una de cuyas fuentes principales, reconocida por él mismo, era la filosofía de San Buenaventura ${ }^{40}$, encontraba su hilo conductor en la defensa apasionada de la Divina Providencia, manifestada principalmente a través de los ángeles custodios. Así, al igual que,

«la tierra produce frutos [tanto] para los buenos como para los malos; las nubes para todos llueven, el ayre a todos alienta, penetra y rodea [...], a ninguno desecha Dios de su gloria, a todos franquea sus auxilios suficientes, a todos quiere comunicar su gracia santificante y a todos da sus Angeles de la Guarda porque pertenecen a este orden de providencia espiritual» ${ }^{41}$.

La Providencia Divina, entendida como el cuidado de Dios por sus criaturas, no excluía, sin embargo, la libertad esencial de éstas. Haciendo uso de su libre albedrío, tanto el diablo como los seres humanos actuarían sin ningún tipo de traba: el diablo, tentando a los hombres, y éstos, sucumbiendo con frecuencia a sus maléficas propuestas. Las tentaciones demoníacas, como origen de posibles males futuros, se hallaban en el centro de las preocupaciones de Blasco Lanuza, quien dedicaba seis capítulos de su segundo tratado a desentrañar su significado. La perseverancia atribuida al diablo y sus secuaces se expresaba contundentemente en el título de uno de dichos capítulos, según el cual, «tienta el demonio en todo lugar, en todo tiempo [y] por medio de todos los sentidos, al

\footnotetext{
38 Vid. María TAUSIET, «La exclusión de las almas: contumaces y descomulgados en los siglos XVI y XVII», en Enrique Martínez RuIz (ed.), Madrid, Felipe II y las ciudades de la monarquía, vol. III (Vida y cultura), Madrid, Ed. Actas, 2000, pp. 395-405.

${ }^{39}$ Francisco Blasco LanuZa, Beneficios, p. 102.

${ }^{40} \mathrm{La}$ tolerancia, benevolencia y optimismo de San Buenaventura - en este caso respecto a la protección incondicional de los ángeles custodios- se extendía asimismo a su postura sobre las almas del purgatorio, cuya esperanza y contento consideraba indudables ante la perspectiva segura de la bienaventuranza. Vid. María TAUSIET, «Gritos del más allá. La defensa del purgatorio en la España de la Contrarreforma», Hispania Sacra, 115 (2005), 81-108.

${ }^{41}$ Francisco Blasco Lanuza, Beneficios, pp. 101-102.
} 
principio de la obra, en medio della y en el fin» ${ }^{42}$. Como aviso y advertencia, Blasco Lanuza describía en otro apartado «los siete modos de tentaciones, figuradas en las siete cabeças del dragon ${ }^{43}$ apocalíptico de San Juan ${ }^{44}$.

Siguiendo la interpretación psicologista de San Antonino de Florencia ${ }^{45}$, estas tentaciones consistirían principalmente en importunar, hacer dudar, irrumpir inesperadamente o en secreto, violentar la voluntad, provocar confusión y, por último, engañar:

«La primera cabeça o tentacion con que el demonio procura entrar a dar su veneno al alma se dize importuna, porque su condicion es importunar continuamente, y sin dejar treguas de paz, induciendo al pecado [...] Otra tentacion se dize dubia [...] quando pone dudas en lo que se deve creer [...] Tercera se dize subita, tentacion pronta que, por ser tan de repente, no puede hazer deliberacion la razon [...] Quarta tentacion se dice occulta, que por ser tan secreta no puede apear su malicia el discurso [...] Quinta se dize violenta porque, violentada la voluntad con temores de perder la vida o gravisimos males, se resuelve en dar consentimiento [...] Sexta se dize perplexa, quando el entendimiento se ve cercado de dos males y [...] no sabe elegir el menor daño [...] Septima tentacion se dize fraudulenta, y es quando la voluntad engañada con apariencia de que es bueno y justo lo que se le propone, da su consentimiento» ${ }^{46}$.

Así pues, la eterna batalla entre el bien y el mal se libraría en primer lugar en la psique individual, a través tanto de los llamados cinco sentidos exteriores, vista, gusto, oído, olfato, tacto, como de los interiores ${ }^{47}$, imaginación, memoria, entendimiento, discurso y voluntad. Según Blasco Lanuza, cada ser humano, en el mismo instante en que Dios cría su alma, esto es, nada más ser concebido en el vientre materno, dispone de un ángel de la guarda, y «los Pontifices, Prelados, Reyes y Ministros, que goviernan a muchos, tienen dos Angeles de Guarda» ${ }^{48}$. Pero, al mismo tiempo, con permisión divina, «pone Luzifer por adversario un demonio a cada hombre para que siempre le persiga», añadiendo «otro segundo demonio a Pontifices, Prelados, Reyes, Principes y a cualquier hombre puesto en dignidad de presidencia» 49 . De acuerdo con esta concepción, las fuer-

42 Francisco Blasco LanuZa, Patrocinio, p. 713.

43 Idem, p. 712.

44 Vid. Apocalipsis, 12, 3.

45 Antonino de Florencia, Summa Theologica Moralis, Venecia, 1477, vol. I, tit. 6, cap. 13.

46 Francisco Blasco LanuZa, Patrocinio, pp. 712-713.

${ }^{47}$ En opinión del autor, uno de los medios más utilizados por el demonio para tentar eran los sueños. Véanse al respecto los versos 789-803 del Libro IV de El Paraíso Perdido de John Milton, en que Satanás tienta por primera vez a Eva mediante un sueño («Allí lo hallan, agachado cual sapo al oído de Eva, con su arte diabólico intentando ganar el órgano de su fantasía y poder forjar así las ilusiones que a él le placen, imágenes y sueños»). Véase asimismo James S. AMELANG, «Durmiendo con el enemigo: el diablo en los sueños», en María Tausiet y James S. Amelang (eds.), El diablo en la Edad Moderna, Madrid, Marcial Pons, 2004.

48 Francisco Blasco LanuZa, Patrocinio, p. 143.

49 Francisco Blasco Lanuza, Patrocinio, p. 483.

Hispania Sacra, LXI

123, enero-junio 2009, 125-146, ISSN: 0018-215-X 
zas angélicas y demoníacas se equilibraban en los conflictos de conciencia particulares. Ello mantenía la incógnita sobre el destino de cada individuo hasta su agonía y tránsito, momento en que la lucha entablada en vida por el ángel y demonio personales se extendía al resto de las potencias celestes e infernales, dispuestas a precipitarse y entrar en fieros combates por conseguir el alma del difunto $^{50}$. La hora de la muerte, esto es, la situación de mayor debilidad e indefensión, se consideraba especialmente propicia a las tentaciones demoníacas, lo que generó una abundante literatura destinada a ayudar a bien morir ${ }^{51}$. Según Tadeo Felipe Cortés del Valle,

«Quando Lucifer y sus ministros reconocen que los hombres tienen mortal enfermedad, al momento se previenen de toda su saña y astucia para derrivar al pobre enfermo con varias tentaciones y, como se les acaba el plazo para perseguir a las almas, quieren recompensar con su ira [...] lo que les falta de tiempo. Se juntan como lobos carnivoros, consideran sus inclinaciones, habitos y costumbres y cuales sean sus afectos mas flacos para hacerles por alli la guerra» 52 .

Para Blasco Lanuza, sin embargo, tales acosos quedaban contrarrestados por la señalada intervención angelical en los llamados «novísimos» o postrimerías del hombre, muerte, juicio, infierno y/o gloria ${ }^{53}$. En realidad, el equilibrio entre los aliados de uno y otro bando con que cada sujeto afrontaba su batalla final venía a representar los continuos conflictos de conciencia librados por unos seres, los humanos, en teoría tan propensos al pecado como a la virtud.

${ }^{50}$ Vid. Peter Marshall, Beliefs and the Dead in Reformation England, Oxford, Oxford University Press, 2002.

${ }^{51}$ Entre otros tratados en español sobre el tema pertenecientes a la Edad Moderna, merece la pena destacar: Alexo VenEgas, Agonia del transito de la muerte, Toledo, 1553; Jaime MonTAÑÉs, Espejo y arte muy breve y provechoso para ayudar a bien morir en el incierto dia y hora de la muerte, Valencia, 1565; Juan Polanco, Regla y orden para ayudar a bien morir a los que se parten de esta vida, Zaragoza, 1578; Melchor DE YEBRA, Refugium infirmorum, en el cual se contienen muchos avisos espirituales para socorro de los afligidos enfermos y para ayudar a bien morir a los que estan en lo ultimo de su vida, Madrid, 1593; Martín CARRILlo, Tratado de ayudar a bien morir, Zaragoza, 1596; Antonio ALVARADO, Arte de bien morir, guia del camino de la muerte, Madrid, 1611; Pedro DE LA FuENTE, Paso riguroso del Iordan de la muerte y avisso al hombre interior, para morir y vivir bien, Sevilla, 1640; Pedro Nolasco, Prevencion para la hora de la muerte, Madrid, 1687; Carlos BundeTo, El espejo de la muerte, en que se notan los medios de prepararse para morir, Amsterdam, 1700, y Tadeo Felipe CoRTÉs DEL VALLE, Escuela de la muerte, Burgos, 1765 (Vid. Máximo GarCÍA FERnÁNDEZ, Los castellanos y la muerte. Religiosidad y comportamientos colectivos en el Antiguo Régimen, Valladolid, Junta de Castilla y León, 1996, pp. 74-84).

52 Tadeo Felipe Cortés del Valle, Escuela de la muerte, Burgos, 1765, pp. 336-337 (citado en Máximo García Fernández, op. cit., p. 77).

${ }^{53}$ No hay que olvidar que Blasco Lanuza dividía su segundo tratado en tres partes: la primera, dedicada al patrocinio de los ángeles; la segunda, al combate de los demonios; y la tercera, a «los combates que ay entre angeles y demonios por causa de las almas en los ahogos que preceden a la muerte y en el juizio que se sigue a ella.» (Vid. Patrocinio, p. 971). 
En el plano cósmico, no obstante, la balanza entre las fuerzas del bien y el mal se inclinaba de manera clara a favor de las primeras. Ello no significaba que los demonios carecieran de estrategia, ni que su número fuera en modo alguno escaso. Por lo que respecta a la táctica guerrera, según Blasco Lanuza, tanto ángeles como demonios se organizaban como ejércitos presididos por siete generales. Si el seráfico San Miguel contaba con «siete Angeles Superiores, como Principes y Capitanes generales», en el bando infernal, como «Generales de la milicia de Luzifer» actuaban «los siete demonios [...] que presiden a los siete vicios» secundados por «otros muchos Capitanes inferiores a ellos» ${ }^{54}$. En cuanto al número de efectivos, pese a no aventurar ninguna cifra concreta ${ }^{55}$, los símiles utilizados por el clérigo para dar una idea de la inmensidad demoníaca hablan por sí mismos:

«Ay tantos demonios entre nosotros que dizen gravissimos autores andan tan espesos como atomos:

Dixo el Espiritu Santo en el libro de Josue que eran los enemigos de Dios como las arenas del mar [...] Son mas los demonios conspirados contra los hombres que los polvos [...] Andan a vezes entre nosotros mas espesos que los atomos que vemos en los rayos del sol [...], aquellos incomprehensibles polvillos que se descubren quando entra el rayo del sol por la ventana [...] Mas son que los cabellos de mi cabeça los que con odio mortal me persiguen ${ }^{56}$.

Aun así, la superioridad numérica de los ángeles resultaba incuestionable:

«Las tropas de los Angeles son infinitas en cierto modo, y solo podemos decir que son innumerables y exceden a toda la aritmetica de los hombres. Los motivos que Dios tuvo para criar tan copioso numero [fueron] su misma bondad y omnipotencia [...] Preguntan los sagrados interpretes si exceden los Angeles al numero de los hombres, computando cuantos precedieron y naceran desde Adan al ultimo. Y es comun parecer que son mas [...] Y pruevan muchos graves escritores que los mas encumbrados son en mayor numero, esto es, que en los Serafines ay mas legiones que en los Cherubines, y en estos mas que en los Tronos, y assi en los demas, guardando su proporcion. Porque lo mas perfecto [...] esta mas multiplicado» ${ }^{57}$.

54 Para una descripción de la organización militar de los ángeles y los demonios, véanse los capítulos quinto (libro I, parte $2^{\mathrm{a}}$ ) y décimo (libro II, parte $1^{\mathrm{a}}$ ) respectivamente de Patrocinio, pp. 215-223 y 487-490.

55 Según Johan Wier o Weyer, los demonios sumaban un número de 7.409.127 y se hallaban bajo la dirección de 79 príncipes. Otros expertos en el tema proporcionaron cifras aún más desorbitadas, como la de 1.758.640.176, resultado de la supuesta existencia de 6 legiones de demonios divididas en 66 cohortes que contenían 666 compañías de 6.666 individuos. No obstante, la fórmula comúnmente más admitida para conocer el número exacto de demonios era la multiplicación del gran número pitagórico por 6, es decir, 1.234.321 x 6, lo que arroja la cifra de 7.405.926. Vid. Johan WIER, De praestigiis daemonum et incantationibus ac veneficiis. Libri sex, Basilea, 1563.

56 Francisco Blasco LanuZa, Patrocinio, pp. 465-466.

${ }^{57}$ Francisco Blasco LanuZa, Beneficios, pp. 160-162.

Hispania Sacra, LXI

123, enero-junio 2009, 125-146, ISSN: 0018-215-X 
Por si quedara alguna duda, la prueba irrefutable para Blasco Lanuza de la mayoría angelical -no sólo respecto a los hombres, sino también a los demonios- se hallaba en el episodio de la caída:

«Si se pregunta, ¿quantos cayeron del Cielo, arrastrados del peso de su sobervia? [...] Comparados con los Angeles Santos que quedaron en la gloria, cayeron solo una dezima parte» 58 .

La aceptación de esa décima parte, denominada por algunos «el décimo coro de los ángeles» («porque cayeron tantos de cada uno de los nueve ordenes que podian hazer un coro ygual en numero a qualquier de los nueve» ${ }^{59}$ ), implicaba el reconocimiento por parte del clérigo de una ventaja del bien sobre el mal mucho más obvia que la contemplada en el libro del Apocalipsis, según el cual la proporción de ángeles caídos habría sido de un tercio ${ }^{60}$.

Siendo tan evidente la superioridad de los ejércitos celestiales, ¿cómo explicar entonces los desgraciados sucesos que conmovieron las montañas de Jaca al menos durante cinco años? ¿Cómo entender una «invasion de demonios» tal que ninguna fuerza humana o divina parecía capaz de detener? En realidad, las casi mil doscientas páginas del tratado sobre la interminable lucha entre ángeles buenos y malos no tenían otro fin que tratar de encontrar una respuesta satisfactoria al problema del sufrimiento y el mal simbolizado en todo tipo de ataques satánicos. Uno de los más extraordinarios, al decir de su autor, había sido el presenciado por él mismo a raíz de la epidemia de posesión demoníaca descrita en estas páginas: en palabras del propio Blasco Lanuza, «aunque se hallan escritos muchos sucessos de personas espiritadas, y en todos siglos se han experimentado estas infestaciones de Satanas [...] dudo que haya precedido otro de mayor asombro en el mundo al que aora poco ha vimos en el pueblo de Tramacastilla, pueblo en las Montañas de Iacca, y Reyno de Aragon» ${ }^{61}$.

De este modo, aun partiendo de la base de que la Divina Providencia, Dios mismo, constituye por definición un misterio para el hombre y que la incógnita del mal no se despejará hasta el momento del Juicio Final, en uno de los capítulos más significativos de su libro, Blasco Lanuza se aventuraba a proponer algunas de las «razones» por las que Dios permitía a los demonios apoderarse de

58 Francisco Blasco LanuZa, Patrocinio, p. 462.

59 Idem.

60 «Aparecio en el cielo otra señal: un gran Dragón rojo [...] Su cola barrió la tercera parte de las estrellas del cielo y las arrojó a la tierra» (Apocalipsis, 12,4). Nótese que, siguiendo la interpretación apocalítptica, John Milton atribuía también dicha proporción al número de los caídos: «¿Eres tú el Ángel traidor que [...] atrajo a sí a un tercio de los hijos del Cielo, conjurándolos en contra del Altísimo [...]?» (El Paraíso Perdido, Libro II, versos 689-693)

${ }^{61}$ Francisco Blasco Lanuza, Patrocinio, p. 834 
ciertos seres humanos ${ }^{62}$. Es ahí donde, tras exponer la doctrina clásica de autores como San Buenaventura, Blasco Lanuza se refería a un motivo concreto -la mayor gloria de Dios- desde un punto de vista más político que propiamente teológico. Un mal tan extremo no podía justificarse únicamente como castigo por ciertos pecados de sus víctimas o ajenos, como advertencia acerca de los sufrimientos del infierno, o como una demostración del libre albedrío concedido tanto a hombres como a demonios, sino como una ocasión para mostrar la victoria definitiva de Dios en el combate contra un enemigo tanto más poderoso cuanto más daño era capaz de infligir. Para Blasco Lanuza, además, la grandeza y superioridad divinas se hallaban ligadas al poder de la Iglesia católica para expulsar a los demonios a través de sus exorcistas, lo que debía servir de luz a los herejes y ateos ${ }^{63}$ en relación con sus errores:

«Uno de los motivos por que aora se descubren tantos espiritados es porque se dilata el error de los hereges Ateystas en la Francia, y previene la piedad Divina este antidoto contra esta ponzoña de almas en nuestra España, disponiendo que den evidentes muestras los mismos demonios, que estan secretos en los cuerpos, de su ciego error [...] Oxala que ahora, en estos Reynos de España, con la entrada de los Franceses en el de Cataluña, no se vaya estendiendo esta ponzoña. Podemos bien colegir que le prohibe el paso la providencia divina, dando claros desengaños a gente ruda y poco fundada en la $\mathrm{Fe}$, con experiencias tan notorias [como] el sucesso de obsessas mas ruydoso que se ha visto en muchos siglos [...] en el lugar de Tramacastilla y Valle de Tena, que confina con la Francia, y Principado de Bearne y Begorra» ${ }^{64}$.

Entendida como tal «antídoto», la posesión habría sido, por tanto, un mal destinado por Dios a prevenir otro mal todavía peor: la extensión de la herejía protestante a través de una comarca estratégica que constituía uno de los pasos más frecuentados y, en consecuencia, más peligrosos entre Francia y España. Desde un punto de vista práctico, la lucha de los exorcistas católicos contra los demonios suponía, además de un triunfo contra el Maligno y contra las ideas protestantes, una forma de evangelizar o aculturizar ciertas zonas montañosas donde muchas costumbres paganas todavía persistían en pleno siglo XVII ${ }^{65}$. Según el inquisidor Bartolomé Guijarro,

62 «Capitulo XVII, libro II, $3^{\text {a }}$ parte: «Que ay muchas y gravissimas razones para permitir Dios, o mandar a los demonios, que entren en los cuerpos humanos. Es doctrina admirable.» (Vid Patrocinio, pp. 816ss).

${ }^{63}$ En el siglo XVII, herejía y ateísmo eran dos conceptos que solían aparecer unidos, existiendo una confusión y mezcla entre ambos. En realidad, el término ateo se utilizaba para designar la actitud de los opuestos a cualquier doctrina teológica predominante. Vid. Michael HunTER, «The Problem of 'Atheism' in Early Modern England», TRHS, 35 (1985), David WoOTTON, «Unbelief in Early Modern Europe», History Workshop, 20 (1985) y Michael HunTER y David WoOTTON (eds.), Atheism from the Reformation to Enlightenment, Oxford, Clarendon Press, 1992.

64 Francisco Blasco Lanuza, Patrocinio, p. 818.

65 Sobre la persecución de la brujería como una forma de aculturación, vid. Stuart CLARK, «Accul-

Hispania Sacra, LXI

123, enero-junio 2009, 125-146, ISSN: 0018-215-X 
«siguese utilidad al hombre de permitir Dios que el demonio entre en sus cuerpos porque con eso ocasiona a frecuentar mas los Santos Sacramentos, ejercitarse en obras espirituales y santas y en el amor divino. Y esta es, a mi ber, la causa porque permite Dios estos males en las montañas, y no en la tierra llana, porque conociendo Dios que la gente de aquella tierra necesita de semejantes remedios, como Padre y Medico Espiritual, les da enfermedades que se curan con ellos [...] y assi parece que [...] lo permite Dios en estas montañas de Iacca, donde por la aspereza de la tierra y corto natural de sus abitadores ay poca noticia de las cosas de Nuestra Santa Fe»66.

Más allá de consideraciones de orden partidista o pragmático, la visión de Blasco Lanuza acerca de la posesión demoníaca constituye una meditación acerca del mal y su aparente incompatibilidad con la Providencia Divina. Tras su exposición de los posibles motivos por los que Dios permite la entrada de demonios «a dar fuertes garrotes al cuerpo», el clérigo insistía en que, por más que lo intente, el hombre no puede llegar a saber nada, debiendo confiar en la sabiduría y bondad divinas: «por ser los secretos juyzios de Dios muy escondidos a nuestra industria, solo sabemos de cierto que no lo permite sin causa justa» ${ }^{67}$. Sus aproximaciones al peliagudo y controvertido asunto de la Divina Providencia $^{68}$ se enmarcan en las reflexiones sobre el mismo tema de otros autores contempóraneos como Francisco de Quevedo ${ }^{69}$ o John Milton ${ }^{70}$, que también dedicaron una parte importante de su obra a dilucidar un misterio irresoluble, pero no por ello menos inquietante.

Uno de los aspectos más difíciles de entender acerca de los secretos de la Providencia, al que Blasco Lanuza consagraba varios capítulos de su tratado, era por qué suelen ser los justos quienes más sufren y más insistentemente son acosados por el demonio. Como una forma de consuelo menor, el clérigo glosaba la sentencia popular según la cual «pagan justos por pecadores», afirmando

turation by Text» en su Thinking with Demons. The Idea of Witchcraft in Early Modern Europe, Oxford, Oxford University Press, pp. 509-525.

${ }^{66}$ Memorial de Bartolomé Guijarro y Carrillo al Tribunal de Zaragoza sobre su visita a Tena (sin fecha), AHN, Inq., Lib. 976, fols. 310 v-311r.

${ }^{67}$ Francisco Blasco LanuZa, Patrocinio, p. 820.

68 Para un estudio en profundidad sobre el tema, vid. Alexandra WaLsham, Providence in Early Modern England, Oxford, Oxford University Press, 1999.

69 Vid. Francisco De Quevedo y Villegas, Providencia de Dios, padecida de los que la niegan, y gozada de los que la confiesan. Doctrina estudiada en los gusanos y persecuciones de Job $\left[1^{\mathrm{a}}\right.$ ed., Zaragoza, 1700] y La constancia y paciencia del Santo Job en sus pérdidas, enfermedades y persecuciones [1 $1^{\mathrm{a}}$ ed., Madrid, 1713], en Aureliano Fernández-Guerra y Orbe (ed.), Obras de D. Francisco de Quevedo Villegas, Biblioteca de Autores Españoles, vol. 48, Madrid, 1951, pp. 165-248. Como advierte el editor, en 1713 ambas obras fueron publicadas conjuntamente, añadiéndose a la primera un significativo frontispicio según el cual dicho tratado probaba «la Providencia de Dios, para consuelo y aliento de los católicos y vergonzosa confusión de los herejes».

70 Vid. John Milton, Areopagitica [1 ${ }^{\mathrm{a}}$ ed., Londres, 1642], (trad. esp. en Torre de Goyanes, Madrid, 1999), y El paraíso perdido [1 ${ }^{\mathrm{a}}$ ed., Londres,1667]. 
«que castiga Dios muchas vezes, o açota, a justos, para reduzir y poner terror a pecadores». Y como ilustración de la misma añadía el ejemplo siguiente:

\begin{abstract}
«Quando quiere el hombre sugetar a un leon bravo, no le sacude con vara a el, porque, picado del açote, daria brincos que romperian cadenas y despedazaria al que topasse. Para amedrentarlo con suavidad, toma un perrillo y en su presencia lo açota fuerte. ¿Y que se sigue? Viendo el leon los saltos, alaridos y pena del perrillo, se retira, tiembla, se rinde y sugeta, tanto que le llevan de una en otra ciudad como corderillo. Assi hace Dios para convertir grandes pecadores, sabe que si los castigos llegassen a sus personas, serian peores, indignarianse contra el mismo Señor [...] y, para rendirlos con suma benignidad, toma a un justo, perrillo obediente y agradecido; a una niña; a otra virtuosa y, dando lugar al demonio, [...] permite que sacuda tales golpes que ponga assombro a los que en malicia son fieros leones y se conviertan, considerando que si a los justos trata el demonio con este rigor, ¿que tal sera con los pecadores?» ${ }^{71}$.
\end{abstract}

Este consuelo, simplista y difícil de aceptar por las víctimas de una justicia divina supuestamente obligada a valerse de estrategias, representaba tan solo un ejemplo más en un tratado en que la casuística escolástica todavía desempeñaba un papel importante.

En realidad, la tesis principal de Blasco Lanuza para dotar al mal de auténtico significado se basaba ante todo en una entusiasta y firme apología del libre albedrío. Así, del mismo modo que John Milton defendía por las mismas fechas libertades fundamentales como las de conciencia, expresión e imprenta, de forma directa en su Areopagitica, y, más o menos velada, en el resto de su producción literaria, Blasco Lanuza insistía en que el bien sólo tenía sentido desde la libertad para rechazarlo y que, por tanto, era algo que había que conquistar tras una lucha consciente y esforzada. Que los demonios salieran a la luz no significaba que el mal se hallara más o menos presente, sino tan solo que podía ser más fácilmente reconocido gracias a la batalla que debía librar con las fuerzas opuestas. Visto de este modo, el mérito se cifraba en el combate perpetuo, y no en una aparente paz que ocultaba insospechados demonios o males secretos prestos a estallar en cualquier momento:

«Nunca se descubren nuestros enemigos donde hallan buen acogimiento [...] Nadie entienda que estan ausentes los demonios de aquellos hombres que no son afligidos sensiblemente dellos [...] Hazen mayores ruidos donde son menos reverenciados, aunque sean pocos en numero, y, al contrario, aunque sean infinitos, apenas se perciben donde quedan servidos, porque el buen hospedaje les obliga a dar indicios de paz. No se hallan combates sino en disensiones opuestas; donde hay conformidad de animos todo esta quieto, hasta el tiempo en que el Señor viniere a descubrir las verdades. Por esso ay mas demonios, pero secretos, donde tienen paz y treguas» ${ }^{72}$.

\footnotetext{
${ }^{71}$ Francisco Blasco LanuZa, Patrocinio, p. 826.

72 Francisco Blasco Lanuza, Patrocinio, pp. 828-829.
} 
La calma aparente, el «bien» que no se exponía al conocimiento y el contacto directo con el mal, representaba para Blasco Lanuza el auténtico peligro: «Esta paz es guerra mortal» ${ }^{73}$. Desde ese punto de vista, por paradójico que pudiera parecer, las personas realmente virtuosas serían aquéllas asediadas por muchos males o demonios, como demostraban ejemplos tan palpables como los de Santa María Magdalena de Pazzi ${ }^{74}$ o «Santa Teresa de Iesus, prodigio de Santidad, que permitio Dios la atormentasen, como al Santo Iob, muchas veces» ${ }^{75}$. Ello consentía al clérigo arrojar cierta luz sobre el hecho de que, en su opinión, las afectadas por la epidemia de posesión demoníaca del valle de Tena habían sido «solo mugeres de buena vida» 76 .

Siguiendo la interpretación providencialista, de modo similar, aquellos parajes donde aparecían energúmenos eran para Blasco Lanuza lugares especialmente sagrados, de ahí el significativo título de uno de los capítulos de Patrocinio según el cual: «Es digna de alabanza la tierrra o poblado donde se descubren obsesos y exercitados del demonio. Verdad poco entendida del vulgo» ${ }^{77}$. Este juicio venía a contradecir el expresado por el inquisidor Guijarro, para quien la presencia demoníaca se hallaba directamente ligada, en el caso de las montañas de Iacca, a la «ydolatria y poca firmeza en la Fee» de sus rudos habitantes ${ }^{78}$. Sin entrar en consideraciones sobre el elogio de Blasco Lanuza ni el menosprecio de Guijarro, lo cierto es que las condiciones tanto materiales como espirituales en que vivían los habitantes de las localidades donde se manifestaron los síntomas de posesión eran particularmente duras. Así se refleja con claridad en el siguiente párrafo de una carta firmada en octubre de 1642 por la Junta del Valle de Tena, solicitando al rey que no les hiciera enviar tropas a la guerra de Cataluña:

\footnotetext{
73 Idem, p. 829.

74 Idem, p. 833 ( « ¿No veys vosotras, dezia la Santa Maria Madalena de Pazzi hablando con las monjas, que todo el monasterio esta lleno de demonios? Y [...] tomava una cruz en una mano y en otra una disciplina y dava [...] golpes a una y otra parte para echarlos.»)

75 Idem, p. 833. Acerca de las luchas mantenidas por ambas santas con el demonio, vid. Armando MagGi, Satan's Rhetoric. A Study of Renaissance Demonology, Chicago, University of Chicago Press, 2001, pp. 137-179, y Alison WebER, «Saint Teresa, Demonologist», en Anne J. Cruz y Mary Elizabeth PERRY (eds.), Culture and Control in Counter-Reformation Spain, Minneapolis y Oxford, 1992, pp. 171-195. Sobre los combates de los santos con el demonio en general, vid. José Luis SÁNCHEZ LORA, «Demonios y santos: el combate singular», en María TAusiet y James S. AmElang (eds.), El diablo en la Edad Moderna, Madrid, Marcial Pons, 2004.

76 «Muchas vezes repare, viendo tanto numero de espiritadas en la Valle de Tena, que ninguna vi, de las que tenian opinion de pecadoras o hechizeras, con esse achaque; solo mugeres de buena vida, donzellas sin indicios de graves culpas; niñas de 4, 5, 6, 7 años.» (Francisco Blasco LanuZa, Patrocinio, p. 830).

77 Francisco Blasco Lanuza, Patrocinio, p. 828.

78 Memorial de Bartolomé Guijarro y Carrillo al Tribunal de Zaragoza sobre su visita a Tena (sin fecha), AHN, Inq, Lib. 976, fol. 429.
} 
«A causa de ser la tierra mas esteril que hay en estas montañas, son los lugares de esta valle de poblacion muy tenue. Y asi, toda la acienda de sus vecinos consiste en una miseria de ganado menudo tras del qual, de ordinario, van los mas de sus dueños, dejando como dejan solas a sus mujeres con la demas familia y criaturas en sus casas para que cuyden dellas, y mayor y principalmente desde los ultimos del mes de octubre a los de mayo que, por conservar su corto caudal, viajan a la tierra llana con sus ganados a herbajarlos y restar con ellos asta que los buelben a las montañas» ${ }^{79}$.

Evidentemente, la presencia de «demonios» en la comarca se hallaba estrechamente ligada a las penurias económicas descritas, y también a la casi total ausencia de hombres en las montañas durante la mayor parte del año, lo que implicaría un alto nivel de tensión sexual entre unas mujeres condenadas a la soledad y al abandono marital. Pedro de Arruebo, acusado como brujo y responsable principal de todos los males, era uno de los escasos hombres que permanecían en su casa todo el año. De ahí que sus constantes requerimientos amorosos -acompañados de amenazas contra aquellas mujeres que no se le rendían- se tradujeran con frecuencia en todo tipo de enfermedades y angustias, que las propias afectadas achacaban al hecho de «no haber querido satisfacer los deseos de dicho Arruebo» ${ }^{80}$. El miedo a denunciarlo, así como la alternancia entre el deseo y la negación del mismo ${ }^{81}$, provocaban en las «endemoniadas» una constante ambivalencia de sentimientos expresada sobre todo en sus reacciones frente a lo sagrado una intensa religiosidad frente a airados episodios de sacrofobia como continuas blasfemias o la negación a confesarse ${ }^{82}$.

La batalla personal entre sentimientos contrarios aparecía ejemplificada por el propio Blasco Lanuza en uno de sus numerosos relatos acerca de las endemoniadas:

«Un hombre, que fue muy indiciado de hechizero y preso por el Tribunal del Santo Oficio, deseo alcançar a una de las donzellas obsessas ofreciendola el remedio de su pena si le dava gussto en lo que pretendia. Ella era temerosa de Dios y muy virtuosa [...]. Un dia la encontro en desierto, entre el lugar de Tramacastilla y otro vezino. Alegrose con su

${ }^{79}$ Acto público de respuesta a una carta de su Majestad hecho en la Junta del Valle de Tena (5 de octubre de 1642), Archivo Provincial de Huesca, Sección Protocolos,Tramacastilla, M. A. Sorrosal, fol. 143r. (Citado en Ángel Gari, op. cit., p. 209).

${ }_{80}$ Memorial de la visita al Valle de Tena de fray Raimundo Sáenz. (26 de noviembre de 1638), AHN, Inq., Lib. 976, fol. 164v.

81 «Todas quantas padecen dichos accidentes son o mujeres que dicho Pedro de Arruebo a procurado gozar, o hijas o deudas de aquellas a quien el dicho Pedro de Arruebo amenazo, o mugeres que no an querido tercear con los que el pretendia o hacer otras cosas que el les ha pedido. Y todas, quando estan arrepticias, gritan que su amo es Pedro de Arruebo». Memorial de la visita al valle de Tena de Fray Raimundo Sáenz (28 de noviembre de 1638), AHN, Inq., Lib. 976, fol. 165v.

82 Para un análisis más extenso de los síntomas de las endemoniadas, vid. Ángel GARI, op. cit., pp. 185-201.

Hispania Sacra, LXI

123, enero-junio 2009, 125-146, ISSN: 0018-215-X 
buena dicha; dixola con ternuras que se aguardase, porque queria tratar de su salud. Saco pan y una mançana para que comiese, pero no quiso ella, diziendo que era Viernes y ayunava. Luego saco una redomita de vino blanco, y la porfiaba a que bebiesse, pues el beber no quebrantaba el ayuno. No le fue posible que ella concediesse, y viendola tan fuerte, hecho mano de armas mas sutiles» ${ }^{83}$.

El relato continuaba narrando cómo el hombre había invocado a ciertos demonios, «tres hombres en traxe frances», que se colocaron «al lado siniestro de la mujer», ante lo cual ella comenzó a sentir «fortissimas tentaciones de sensualidad»,

«pero azia la mano derecha se vio muy fortalezida, que le parecia experimentava claramente la asistencia y presidio de su Angel Custodio, con que salio victoriosa» ${ }^{84}$.

Una vez más, tanto en el plano individual como en el cósmico, la aparición del mal con la consiguiente batalla entre opuestos, no era para Blasco Lanuza sino una ocasión para que los ángeles, como fieles servidores del Bien Supremo, terminaran logrando una victoria segura. El éxito de todo combate espiritual gracias a la cercanía, solicitud y fidelidad incondicional de los ángeles representaba para el género humano la mejor garantía de salvación. A decir verdad, la distancia entre ángeles, en teoría, seres perfectos que no habían sucumbido a la caída, y hombres, en su estado de caída transitoria, no era tan grande, teniendo en cuenta la constante familiaridad entre ambos y la suerte común que les aguardaba ${ }^{85}$. No sólo es que los hombres estuvieran destinados a convertirse en ángeles, y a ocupar aquellos asientos vacantes dejados por los que cayeron: es que, ya en este mundo, ambos colaboraban de modo complementario en un mismo proyecto divino. Como expresaba San Buenaventura haciendo gala de un humanismo precursor que venía a equiparar lo humano y lo divino con una rotundidad conmovedora:

«El hombre tiene habilidad para caer con frecuencia, pero para levantarse también; en cambio el ángel, que se mantiene en su estado, tiene la perpetuidad en ese estado, pero si cae, tiene la imposibilidad para levantarse. Por eso el ángel que se mantiene en pie sostiene al hombre, o la debilidad humana, y el hombre, al levantarse, restaura la ruina de los ángeles. Por eso el ángel, en cierto modo, es para el hombre, y en cierto modo también el hombre para el ángel, y en este orden son iguales» 86 .

83 Francisco Blasco LanuZa, Patrocinio, p. 853.

84 Idem, p. 854.

85 Sobre el «parentesco» entre ángeles y seres humanos, vid. David KECK, op. cit., p. 16, y Pedro CóRDOBA, «Au croisement du spirituel et du réel: la place de l'ange dans l'émergence de la famille moderne», en Augustin Redondo (ed.), Les parentés fictives en Espagne (XVIe-XVII siècles), París, La Sorbonne, 1988, pp. 101-120.

${ }^{86}$ San Buenaventura, Comentarios a las sentencias de Pedro Lombardo, libro II (Citado en Étienne Gilson, La filosofía de San Buenaventura, Buenos Aires, Desclée de Brouwer, 1947, p. 241). 
La presencia angelical impregnando el universo, a la que Blasco Lanuza dedicaba su voluminoso tratado, invisible, pero constante y ubicua, expresaría no sólo la solidaridad interna que unía a todas las criaturas, sino también los secretos designios de Dios, siempre favorables a los hombres, pese a la confusión y el sufrimiento debidos a sus interminables errores y conflictos. ${ }_{i} \mathrm{OOh}$, infinita bondad, bondad inmensa, que hará todo este bien surgir del mal, y el mal volverse bien [...] lleno de duda estoy si arrepentirme ahora del pecado cometido [...] o alegrarme mucho más de que un mayor bien nazca!»87, hacía exclamar Milton a un Adán mucho más sabio después de la caída. Y así, del mismo modo, tras superar una de las peores pruebas de su vida, Blasco Lanuza concluía:

«En todo resplandece la suavidad, clemencia y providencia de Dios. Dan los racionales en mil disparates, calumniando las criaturas y al mismo soberano Criador, juzgando mal de lo que se debe alabar. Atencion pido y veran los bienes que su Magestad sabe sacar destos que llamamos pesadissimos males» ${ }^{88}$.

87 John Milton, El Paraíso Perdido, Libro XII, versos 470-476.

${ }^{88}$ Francisco Blasco Lanuza, Patrocinio, p. 816.

Hispania Sacra, LXI

123, enero-junio 2009, 125-146, ISSN: 0018-215-X 